\title{
Suppression of drill-string stick-slip vibration by sliding mode control: Numerical and experimental studies
}

\author{
VAHID VAZIRI, MARCIN KAPITANIAK and MARIAN WIERCIGROCH \\ Centre for Applied Dynamics Research, School of Engineering, University of Aberdeen, Aberdeen AB24 $3 U E$, UK \\ emails:vahid.vaziri@abdn.ac.uk,marcin.kapitaniak@abdn.ac.uk,m.wiercigroch@abdn.ac.uk
}

(Received 13 November 2017; revised 25 April 2018; accepted 25 April 2018; first published online 18 May 2018)

\begin{abstract}
We investigate experimentally and numerically suppression of drill-string torsional vibration while drilling by using a sliding mode control. The experiments are conducted on the novel experimental drill-string dynamics rig developed at the University of Aberdeen (Wiercigroch, M., 2010, Modelling and Analysis of BHA and Drill-string Vibrations) and using commercial Polycrystalline Diamond Compact (PDC) drill-bits and rock-samples. A mathematical model of the experimental setup, which takes into account the dynamics of the drill-string and the driving motor, is constructed. Physical parameters of the experimental rig are identified in order to calibrate the mathematical model and consequently to ensure robust predictions and a close agreement between experimental and numerical results for stick-slip vibration is shown. Then, a sliding mode control method is employed to suppress stick-slip vibration. A special attention is paid to prove the Lyapunov stability of the controller in presence of model parameter uncertainties by defining a robust Lyapunov function. Again experimental and numerical results for the control cases are in a close agreement. Stick-slip vibration is eliminated and a significant reduction in vibration amplitude has been observed when using the sliding controller.
\end{abstract}

Key words: Drill-string dynamics, stick-slip, torsional vibration, nonlinear behaviour, experimental studies, mathematical modelling, sliding mode control

\section{Introduction}

A drill-string is an important component in the drilling rig used for hydrocarbon exploration and production. It might be a few kilometres long and has much similarity with one-dimensional continua such as beams, bars, rods and others. Accordingly, the dominant dynamics of a drill-string should be considered along its length. The dynamics involving the length-wise direction is manifested as stretch and twisting of the drill-string, referred to as axial and torsional vibrations, respectively. The dynamics in the transverse directions in form of various bending modes is commonly referred to as lateral vibration. A very informative introduction to various modes of drill-string vibration is given in [2].

Torsional vibration and, its extreme case, stick-slip have been observed in about 50\% of drilling time [3], where a bit occasionally comes to a complete standstill while the rest of the drill-string continues to rotate. This results in twisting of the drill-string, which 
ultimately leads to a large elastic torque build-up and its subsequent release leading to large torsional acceleration of a drill-bit. The main cause of stick-slip motion is attributed to the velocity dependent nature of the effective frictional torque acting on the drill-string. In particular, the negative slope of the effective frictional torque for higher rotational velocities is the cause of self-excited vibration. Although analysis of stick-slip motion has been described by such velocity-dependent friction models, there has also been alternative models explaining stick-slip by modulations in the normal force caused by coupling between axial and torsional vibration [4-6].

In recent years there have been many attempts to model the drill-string behaviour with focus on the vibrations and control. Saldivar et al. [7] reviewed the existing drilling models and classified them into a few categories such as distributed parameter, coupled Partial Differential Equations (PDEs) and Ordinary Differential Equations (ODEs) and lumped parameter ones. The latest category has an advantage of describing the system dynamics in a simple way, thereby simplifying the analysis for the controller design. Saldivar et al. [7] also reported several different models that have been developed for bit-rock interaction, such as dry friction plus Karnopp's model, forces at the bit-rock interface considering individual cutters, such as works by Detournay [8,9], and Karnopp's model with an exponential decaying friction term.

Drill-string models have been developed for different purposes and some focused on single mode of vibration such as axial or torsional vibrations, whereas others considered coupling between different vibration modes. Ghasemloonia et al. [10] categorized these exiting models in uncoupled and coupled models, as well as reported common boundary conditions for those models and drill-string-wellbore contact models. Within all existing models, one class is the most common model for capturing uncoupled torsional vibration, which has been used by Navarro-López $[11,12]$. These models consist of several parallel disks, rotating around their common axis and connected to each other by torsional spring and damper. Top disk in all these models represents the rotary table and the bottom disk represents the drill-bit. The bit-rock interactions are modeled by the velocity dependent resistive torque acting on the bottom disk. These models have been widely employed in studies focusing in drill-string torsional vibration. The number of disks varies in those studies, for example, 2 disks [13], 3 disks [11,14], 4 disks [15] and even 18 disks [16]. In the current work a 2-disk model has been employed to model the Centre for Applied Dynamic Research (CADR) experimental drilling rig, following the work presented in [13]. However, in our work, the bit-rock interactions are modeled using the experimentally obtained results [17]. It is worth mentioning that recently a new hybrid-systems analysis techniques have been developed to analyse the dynamical systems, such as drill-strings [18].

In last few decades, there have been many attempts to mitigate stick-slip oscillation. Some of the suggestions can be classified as passive control methods, such as drill-string reconfiguration, redesigning the drill-bits, optimisation of the drilling parameters and usage of anti-vibration downhole tools [19]. To avoid stick-slip vibration, traditionally, it is advisable to decrease weight on bit (WOB) and/or increase bit velocity; however, this is not necessarily suitable or most efficient in most cases. Wu et al. [20] introduced the concept of optimum (no-vibration) zone while drilling, which represents the optimal operating conditions. This region is surrounded by others corresponding to low rate of penetration (ROP), stick-slip, backward and forward whirls. This optimum zone is likely 
to disappear completely in hard drilling formations. Therefore, under those conditions, any attempt to control the vibration by adjusting the drilling parameters will most likely fail.

Due to the improvements in the real-time measurement and control systems, the active anti-vibration control methods have attracted significant interest in academia and industry. Some of the main methods are reviewed in [19,21] and these methods can be categorized in four groups based on their control inputs: motor's velocity, motor's torque, WOB or their combinations. For example, Jansen and Van den Steen [22] applied an active damping technique, which controls the top drive velocity. In their study, the electrical variables (current and voltage) have been used to realize the required feedback control. Serrarens et al. [23] also applied $\mathrm{H}_{\infty}$ technique to the motor's velocity to minimize the torsional vibration. In last two years, Al Sairafi et al. [24] and Pehlivanturk et al. [25] used a robust pole placement algorithm and a Proportional Integral (PI) velocity controller with feedback control method to adjust the motor's velocity to suppress the stick-slip.

However, controlling the motor's torque seems to be much more attractive to the researchers. For example, Tucker and Wang [26] explored a method of controlling torsional relaxation oscillations of an active drilling assembly to reduce torsional vibration. Navarro-López and Cortés [27], Hernandez et al. [28] and Liu [15] in different studies used a variation of sliding mode method to control the motor's torque. Bayliss et al. [29] applied pole placement method to obtain controller gain value in order to control the motor's torque. Vromen et al. [16] presented a design of a nonlinear observer-based output-feedback control strategy to vary the motor's torque, and thereby eliminate torsional vibrations.

A few researchers used WOB as a control parameter to suppress stick-slip vibration. Gabler and Bakenov [30] tried to improve drilling efficiency by imposing dynamic loading at the bit-rock interface. Navarro-López and Suarez [13] also proposed a control strategy to suppress stick-slip vibration by manipulating WOB depending on the bit velocity. Another control strategy outlined on [31], known as D-OSKIL, utilizes the WOB as an additional control variable. An experimental implementation of this scheme has been reported in [32], where the authors used a bit and a wooden block to simulate bitrock interactions. Finally, a few researchers used a combination of control parameters to suppress vibration. For example, Puebla and Alvarez-Ramirez [33] used modelling error compensation to control the motor's torque and WOB to suppress the stick-slip vibration.

In addition to all control methods, some attempts have been made toward using observer/estimator-based controller in order to overcome the limitation of accessing downhole real-time measurements. For example, Hong et al. [34] presented simulation results using Kalman estimator to control the stick-slip vibration. Due to the great deal of uncertainties in the model parameters and changing conditions during drilling, any theoretical work must be supported by realistic experimental studies, which are rare.

The main aim of the present work is the experimental validation of a method for suppression of drill-string stick-slip vibration. In addition, we aim at enhancing the current understanding of the underlying complex phenomena occurring in drill-strings. It should also be noted, that the scope of the current paper is limited to the torsional vibration only.

The structure of this paper is as follows. In Section 2, the experimental setup used for the study of drill-string dynamics and control is described. In Section 3, a two degreesof-freedom model is introduced to capture stick-slip, and the techniques employed to 
estimate the model parameters are described. Next, the model is verified in Section 4, where the experimental results and numerical simulation are compared. In Section 5, a sliding mode control method is applied to suppress the torsional vibration. In Section 6, the delay observed in the actuator is first estimated and then included in the model. The control method is experimentally verified showing a successful suppression of the stick-slip vibration. Finally, a discussion of the main results and suggestions for future research are given in Section 7.

\section{Experimental rig}

Uncertainties and difficulties in modelling of drill-string dynamics have motivated researchers to validate their theoretical studies by performing experimental studies. Therefore, several experimental rigs for drill-string dynamics research have been developed with a variety of capabilities. A number of scaled drilling experimental rigs in academic institutions are available to study drill-string dynamics, which have been recently reviewed by Patil and Teodoriu [21]. Most of these rigs consist of a slender drill-string, usually a few meters steel string driven at the top, by a motor through a rotary table. The drill-bit and the bottom hole assembly (BHA) are usually represented in those rigs using discs. The drill-bit and rock interactions during drilling are usually simulated using shakers and brakes. Standard axial excitations and torque profiles are applied onto the discs, in order to study the resulting dynamics of the system. Two example rigs are developed in TU Eindhoven and University of Maryland, described in detail in [35,36], respectively. Some other rigs following the same principle are presented in $[37,38]$.

In addition to these experimental stands, a few rigs use commercial drill-bits and perform drilling in rock samples. For example, Lu et al. [32] used masonry bits, whereas Raymond et al. [39] employed a custom designed drill-bit. Similarly, the rig developed in the University of Minnesota uses special in-house designed bits to drill in rock samples [40]. However, in that setup a rock sample is rotated, while the bit and the BHA are moving axially to induce progression. Also, the torsional flexibility of the drill-pipes is simulated through a special gear-pulley-spring system. Despite drilling real rock samples, this rig neglects the lateral dynamics. In last few years, commercial drill-bits have been employed in a few drilling rigs. The experimental rig developed at the CSIRO laboratory uses the Roller-Cone bits, while neglecting the drill-string dynamics as rigid shaft directly transmits the motor's torque to the bit [41]. Therefore, to our knowledge, none of the laboratory drilling rigs employ real commercial drill-bits and at the same time mimic all modes of vibration of the drill-string.

To cover this gap and be able to replicate all different modes of vibrations, present in the drilling process, a new drilling rig has been designed and built in CADR (described in details in $[17,42])$. This experimental stand is capable of reproducing all major types of drill-string vibration, including stick-slip, whirling and bit-bounce. It allows to investigate nonlinear behaviour between the drill-bit and the drilled formation, as well as to introduce and test different control methods to suppress dangerous vibration. The cutting process is undertaken using real commercial drill-bits and rock samples. The main objective of the rig is to demonstrate the various drill-string vibration phenomena, to verify predictions from the mathematical models describing these phenomena and to implement and verify 

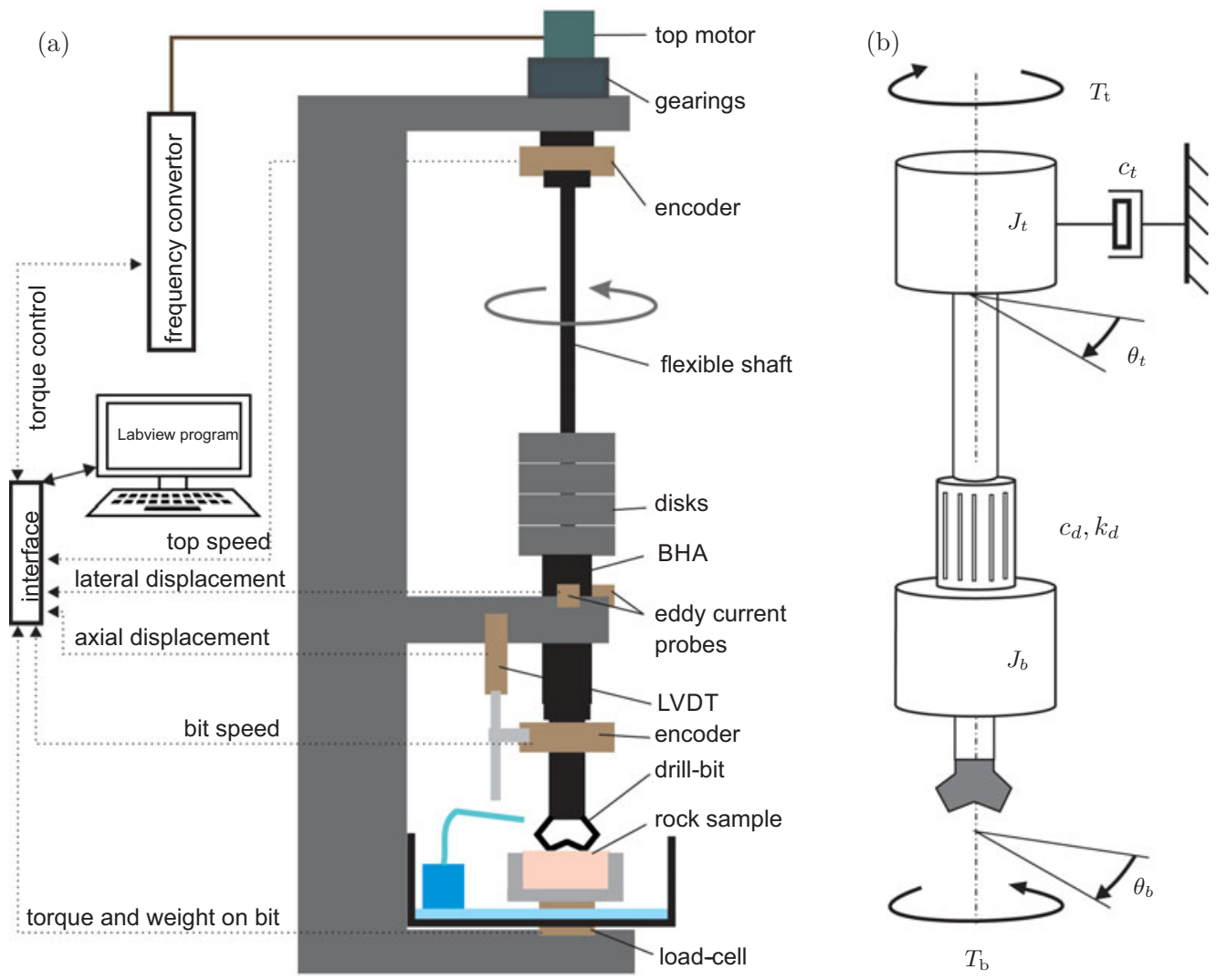

Figure 1. (a) A schematic of the Aberdeen drill-string dynamics experimental rig. The main components of the system are: sensors (top and bottom encoders, eddy current probes, LVDT and four-component load cell), electric motor, flexible shaft, disks, BHA, drill-bit and rock sample. (b) A physical model of a two degrees-of-freedom lump mass torsional system. The viscous damping property of the motor and gearing system and the visco-elasto properties of the pipe are given by $c_{t}, c_{d}$ and $k_{d}$, respectively. The reactive torque acting on the system during drilling is represented by $T_{b}$, adopted from [1].

the proposed control methods. It is worth mentioning that one of the main differences between our rig and commercial rigs is the downhole high-pressure high-temperature (HPHT) conditions, which are difficult to replicate in the laboratory. Therefore, the rig has been used to provide a broader understanding of stick-slip and ultimately to devise means of its suppression.

As shown in Figure 1(a), an three-phase AC motor is connected to the drill-pipe through gearing system. Rotary force transmits to the bit through a drill-pipe (flexible or rigid shaft), BHA and a bit-holder. The top angular velocity is adjustable (from 0 to $1,044 \mathrm{rpm}$ ) and measured by an encoder placed on top of the drill-pipe. The angular velocity of the drill-bit is measured by another encoder connected to the BHA. Horizontal and vertical forces as well as torque coming from the drill-bit to the rock are detected by a load cell placed under the rock sample. ROP of the bit into the rock is measured by a linear variable differential transformer (LVDT) linked to the BHA. 
To observe various drill-string vibration phenomena, flexible shafts are used to mimic the mechanical properties of slender structures like drill-strings. Due to the length of the drill-string, which can be up to several kilometres, the structure has practically no transversal stiffness when compared to the axial direction. This physical configuration can be modelled in a reduced scale by a flexible shaft consisting of many layers of thin wires. Such shafts are used to transmit power in rotating machines as they have high torque capacity transmission and high flexibility. Friction between wire layers plays an important role, which means that an effective damping depends on the tensile load. In the rig, flexible shafts with a diameter of 5, 7, 10, 15 and $20 \mathrm{~mm}$ are tested.

\section{Mathematical modelling}

As mentioned in Section 1, a most common model used for capturing uncoupled torsional vibration consist of several parallel disks, rotating around their common axis, which are connected to each other by torsional spring and damper. In this section, a two degrees-offreedom model is introduced in order to model the drilling rig (Figure 1(b)). The top disk represents the motor and the gearing system (with moment of inertia; $J_{t}$ ), while the bottom disk represents the BHA and the drill-bit (with moment of inertia; $J_{b}$ ). The only possible motion of the top disk is a rotation about an axis fixed in space. This disk is subject to a driving torque $T_{t}$ and to a viscous drag torque proportional to the angular velocity through coefficient $c_{t}$. The visco-elasto properties of the drill-pipe are given by $c_{d}$ and $k_{d}$, respectively. The bit-rock interactions are modeled by the velocity dependent resistive torque acting on the bottom disk. This reactive torque acting on the system during drilling is denoted by $T_{b}$. In this model, the frequency converter is set in the torque control mode and the motor's velocity can be calculated from the equations of motion. Note that this model is just an approximation used to mimic the torsional behaviour of the experimental rig. If it were to be used for the real vertical drilling rig, several additional factors need to be considered, such as interaction between the drill-string and the borehole, as well as coupling between different modes of vibration. Nevertheless, as presented below, this simplified model seems to be capable of capturing torsional drill-string dynamics.

The state variables of this model can be defined as the real vectors $u=\left(\omega_{t}, \theta_{t}, \omega_{b}, \theta_{b}\right)^{T}$. Here, $J_{t}, J_{b}, c_{t}, c_{d}$ and $k_{d}$ are moments of inertia of the motor and the BHA, damping coefficients of the motor and the flexible shaft as well as stiffness of the flexible shaft, respectively. The equations governing the behaviour of the system presented in Figure 1(b) are given by

$$
\begin{aligned}
& J_{t} \ddot{\theta}_{t}+\left(c_{t}+c_{d}\right) \dot{\theta}_{t}-c_{d} \dot{\theta}_{b}+k_{d} \theta_{t}-k_{d} \theta_{b}=T_{t}, \\
& J_{b} \ddot{\theta}_{b}-c_{d} \dot{\theta}_{t}+c_{d} \dot{\theta}_{b}-k_{d} \theta_{t}+k_{d} \theta_{b}+T_{b}=0,
\end{aligned}
$$

which can be written as a system of first-order ODEs as follows:

$$
\dot{u}=\left(\begin{array}{c}
\dot{\omega}_{t} \\
\dot{\theta}_{t} \\
\dot{\omega}_{b} \\
\dot{\theta}_{b}
\end{array}\right)=\left(\begin{array}{c}
J_{t}^{-1}\left(-\left(c_{d}+c_{t}\right) \omega_{t}+c_{d} \omega_{b}-k \theta_{t}+k \theta_{b}+T_{t}\right) \\
\omega_{t} \\
J_{b}^{-1}\left(c_{d} \omega_{t}-c_{d} \omega_{b}+k_{d} \theta_{t}-k_{d} \theta_{b}-T_{b}\right) \\
\omega_{b}
\end{array}\right),
$$


where an overdot denotes differentiation with respect to time $t$, the control input $T_{t}$ is the torque generated by the motor and the function $T_{\mathrm{b}}$ gives the reaction torque. To fully describe the system, the reaction torque $\left(T_{\mathrm{b}}\right)$ needs to be calibrated. In this regard, the empirical torque on bit (TOB) model is used, which has been recently developed in Centre for Applied Dynamics Research [42]. The details are described in [17]. The reaction torque takes the following explicit form:

$$
\begin{aligned}
T_{\mathrm{b}} & =\left\{\begin{array}{l}
T_{\mathrm{b}, \mathrm{st}}, \dot{\theta}_{b}=0 \text { and } T_{\mathrm{b}, \mathrm{st}}<T_{\mathrm{b}, \mathrm{cf}}, \\
T_{\mathrm{b}, \mathrm{cf}}, \dot{\theta}_{b}=0 \text { and } T_{\mathrm{b}, \mathrm{st}} \geqslant T_{\mathrm{b}, \mathrm{cf}}, \\
T_{\mathrm{b}, \mathrm{dr}},
\end{array}\right. \\
T_{\mathrm{b}, \mathrm{st}} & =c_{d}\left(\dot{\theta}_{t}-\dot{\theta}_{b}\right)+k_{d}\left(\theta_{t}-\theta_{b}\right), \\
T_{\mathrm{b}, \mathrm{cf}} & =\frac{2}{3} \lambda_{s} W_{b}, \\
T_{\mathrm{b}, \mathrm{dr}} & =\frac{2}{3} \lambda_{k} W_{b}+\frac{2 W_{b}\left(\lambda_{s}-\lambda_{k}\right)}{\lambda_{d}^{3} \dot{\theta}_{b}^{3}}\left(2-e^{-\lambda_{d} \dot{\theta}_{b}}\left(\lambda_{d}^{2} \dot{\theta}_{b}^{2}+2 \lambda_{d} \dot{\theta}_{b}+2\right)\right)+\frac{1}{2} W_{b} \lambda_{s t r} \dot{\theta}_{b},
\end{aligned}
$$

where $W_{b}$ is WOB, $\lambda_{s}=\mu_{s} R, \lambda_{k}=\mu_{k} R, \lambda_{d}=d_{c} R, \lambda_{s t r}=\mu_{s t r} R^{2}, R$ is radius of the drill-bit, $d_{c}$ is decay rate and $\mu_{s}, \mu_{k}$ and $\mu_{s t r}$ are static and kinematic friction coefficients and Stribeck effect coefficient, respectively. Figure 2 shows the system's three modes of operation. In order to find the current mode of the system when the drill-bit is stuck (mode A), the function $T_{\mathrm{b} \text {,st }}$ needs to be monitored. The stick phase (mode A) terminates when $T_{\mathrm{b} \text {,st }}$ becomes equal to $T_{\mathrm{b}, \mathrm{cf}}\left(\gamma_{f}\right)$. At this point, the reaction torque $T_{\mathrm{b}, \mathrm{st}}$ reaches the break-away torque value $T_{\mathrm{b}, \mathrm{cf}}\left(\gamma_{f}\right)$ and the system is in the slip phase (mode B). As soon as the drill-bit begins to rotate the system is in the slip phase (mode $\mathrm{C}$ ).

\section{Numerical results and experimental verification}

In order to obtain a good agreement between the experimental observations and the mathematical models, a careful estimation of the rig's physical parameters through several sets of experiments has been carried out (details can be found in [17]). It is worth mentioning that in this experiment, the control signal is calculated in LabVIEW and sent through the data acquisition card (DAQ) to a frequency converter, which controls the motor's torque. Note that the control parameter $\left(T_{c}\right)$ of this converter and the estimated torque $\left(\hat{T}_{t}\right)$ are expressed as a percentage as required in the experimental system. Therefore, the first step is to find a way to estimate the absolute value of the torque generated by the motor $T_{t}$ in $\mathrm{Nm}$ and to estimate the relationship between the requested torque $T_{c}$, the estimated torque $\hat{T}_{t}$ and the generated torque $T_{t}$. In this regard, two experiments are designed and performed, which are explained in [17].

An example of stick-slip vibration occurring for $W_{b}=1.79 \mathrm{kN}$ and $T_{t}=39.57 \mathrm{Nm}$ is shown in Figure 3(a) in the form of a time history and a phase portrait. The motor's velocity with sinusoidal characteristics and the drill-bit velocity with stick-slip vibration of almost constant amplitude are shown in blue and red, respectively.

In order to calibrate the model and fit it to the experimental data, parameter values close to the identified ones are applied: $k_{d}=10.00 \mathrm{Nm} / \mathrm{rad}, c_{d}=0.005 \mathrm{~N} \mathrm{~m} \mathrm{~s} / \mathrm{rad}$, 


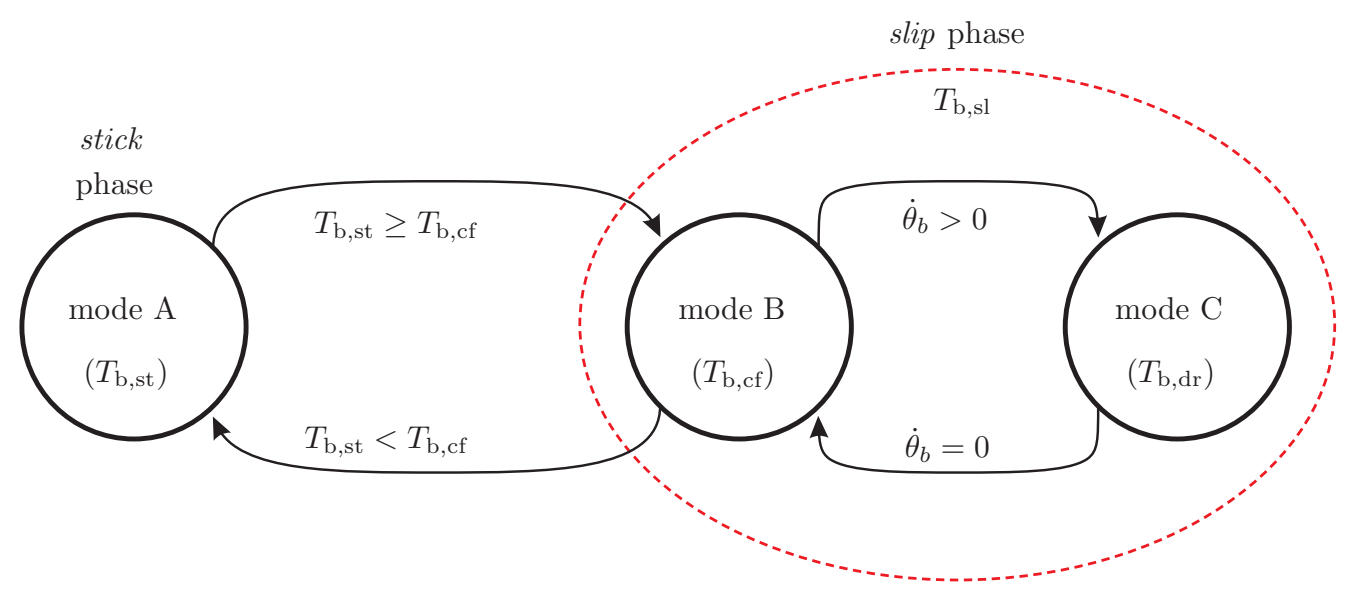

FIGURE 2. The model has two phases: stick phase, which includes one mode of operation (mode A), and slip phase, which has two modes (modes B and C).

$J_{t}=13.93 \mathrm{~kg} \mathrm{~m}^{2}$ and $c_{t}=11.38 \mathrm{Nm} \mathrm{s} / \mathrm{rad}$. A TOB model (equation (3.3)) is used for the TOB formulation, with corresponding parameters shown in Table 1 in [42] for $W_{b}=1.79 \mathrm{kN}$. There is an excellent agreement with the experimental observations, as can be seen when comparing the phase portraits shown in Figures 3(a) and (d). To confirm the TOB model, Figures 3(b) and (c) show zoomed-in views of $10 \mathrm{~s}$ of experimental and numerical results together with TOB recorded in the experiment and modelled by equation (3.3). The motor's velocity in the experiment and the model depicted in black clearly shows very similar behaviour. It can also be seen that the bit velocity in the model is perfectly matched to the experimental data, shown in green and red, respectively. Interestingly, the two phases of the system can be observed in both experimental and modeled TOB data depicted in blue. There is a significant drop in TOB when the stick phase starts. The TOB increases in this phase until reaching the break-away value, after which the system goes to the slip phase.

\section{Suppressing torsional vibration}

In the previous section, the experimental rig was modelled and calibrated. It is worth remembering that in this model the torque $T_{t}$ generated by the motor is the control input of the system. The next step is to design a suitable control method and then to apply it to the model in order to decrease the torsional vibration and eliminate stick-slip vibration while drilling. After considering different methods, described in Section 1, the most suitable method for the proposed model and the experimental rig is the sliding mode controller [15]. This controller is an extended version of the one proposed in [11], which is here re-designed for a two degrees-of-freedom system, taking into account a delay in the actuator. It is worth mentioning, that the main strength of a well-designed sliding mode controller lies in its robustness for systems with parameter uncertainties and possible un-modeled dynamics [43], such as drilling process. In this section, this controller will be applied to the developed model. 
(a)
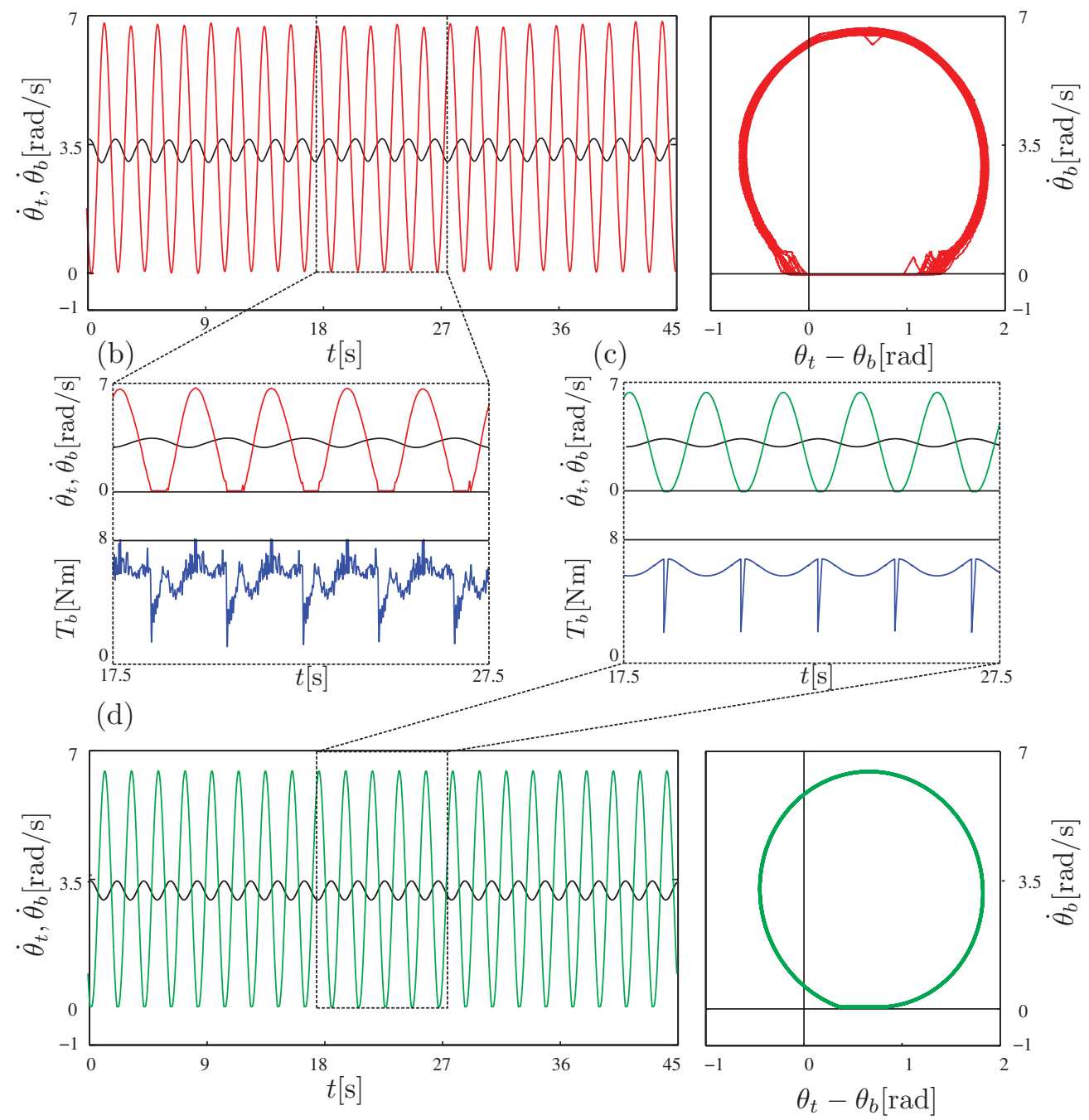

FIGURE 3. An example of stick-slip oscillations occurring in the experimental rig for $W_{b}=1.79 \mathrm{kN}$ and 1.5 in pre-buckled flexible shaft. The time histories of the angular velocities at the bottom, $\dot{\theta}_{b}$, and the top, $\dot{\theta}_{t}$, phase portraits from (a) experimental studies, (d) a low-dimensional model with their $10 \mathrm{~s}$ zoomed-in views in (b) and (c) together with TOB recorded in the experiment and modelled by equation (3.3).

\subsection{Sliding mode control}

The state variables of the two degrees-of-freedom model can be redefined as the real vectors $X=\left(\omega_{t}, \theta_{t}-\theta_{b}, \omega_{b}\right)^{T}$. Note that here the number of states has been reduced to three as for the proposed control method it is enough to know the differences between the top and bottom angular positions instead of both of them. The equation of motion 
Table 1. The estimated parameters and their upper bounds for the controller

\begin{tabular}{lccccc}
\hline \hline Parameter & Value & Unit & Parameter & Value & Unit \\
\hline$\hat{c}_{d}$ & 0.0051 & $\mathrm{~N} \mathrm{~m} \mathrm{~s} / \mathrm{rad}$ & $\hat{c}_{t}$ & 10.47 & $\mathrm{~N} \mathrm{~m} \mathrm{~s} / \mathrm{rad}$ \\
$\hat{k}_{d}$ & 10 & $\mathrm{~N} \mathrm{~m} / \mathrm{rad}$ & $\hat{J}_{t}$ & 13.92 & $\mathrm{~kg} / \mathrm{m}^{2}$ \\
$\epsilon_{c d}$ & 0.00255 & $\mathrm{~N} \mathrm{~m} \mathrm{~s} / \mathrm{rad}$ & $\epsilon_{c t}$ & 3 & $\mathrm{~N} \mathrm{~m} \mathrm{~s} / \mathrm{rad}$ \\
$\epsilon_{k d}$ & 5 & $\mathrm{~N} \mathrm{~m} / \mathrm{rad}$ & $\epsilon_{J t}$ & 2 & $\mathrm{~kg} / \mathrm{m}^{2}$ \\
\hline \hline
\end{tabular}

can be written as a first-order ODEs as follows:

$$
\dot{X}=\left(\begin{array}{c}
\dot{x_{1}} \\
\dot{x_{2}} \\
\dot{x_{3}}
\end{array}\right)=\left(\begin{array}{c}
J_{t}^{-1}\left(-\left(c_{d}+c_{t}\right) x_{1}+c_{d} x_{3}-k_{d} x_{2}+T_{t}\right) \\
x_{1}-x_{3} \\
J_{b}^{-1}\left(c_{d} x_{1}-c_{d} x_{3}+k_{d} x_{2}-T_{b}\right)
\end{array}\right)
$$

Substituting a new state vector $X$ in equation (3.3) gives

$$
\begin{aligned}
& T_{\mathrm{b}}= \begin{cases}T_{\mathrm{b}, \mathrm{st}}, & x_{3}=0 \text { and } T_{\mathrm{b}, \mathrm{st}}<T_{\mathrm{b}, \mathrm{cf}}, \\
T_{\mathrm{b}, \mathrm{cf}}, & x_{3}=0 \text { and } T_{\mathrm{b}, \mathrm{st}} \geqslant T_{\mathrm{b}, \mathrm{cf}}, \\
T_{\mathrm{b}, \mathrm{dr}}, & x_{3}>0,\end{cases} \\
& T_{\mathrm{b}, \mathrm{st}}=c_{d}\left(x_{1}-x_{3}\right)+k_{d} x_{2}, \\
& T_{\mathrm{b}, \mathrm{cf}}=\frac{2}{3} \lambda_{s} W_{b}, \\
& T_{\mathrm{b}, \mathrm{dr}}=\frac{2}{3} \lambda_{k} W_{b}+\frac{2 W_{b}\left(\lambda_{s}-\lambda_{k}\right)}{\lambda_{d}^{3} x_{3}^{3}}\left(2-e^{-\lambda_{d} x_{3}}\left(\lambda_{d}^{2} x_{3}^{2}+2 \lambda_{d} x_{3}+2\right)\right)+\frac{1}{2} W_{b} \lambda_{s t r} x_{3},
\end{aligned}
$$

where all parameters are defined as before. In order to find the fixed points of the system, the equation $\dot{X}=0$ is considered. Two fixed points can be found for the two modes of the system as follows:

$$
\begin{aligned}
& \dot{\theta}_{b}=0 \Rightarrow \bar{X}_{s t}=\left(\bar{x}_{s t 1}, \bar{x}_{s t 2}, \bar{x}_{s t 3}\right)^{T}=\left(0, T_{t} / k_{d}, 0\right)^{T} \\
& \dot{\theta}_{b}>0 \Rightarrow \bar{X}_{s l}=\left(\bar{x}_{s l 1}, \bar{x}_{s l 2}, \bar{x}_{s l 3}\right)^{T}=\left(\omega_{s l},\left(T_{t}-c_{d} \omega_{s l}\right) / k_{d}, \omega_{s l}\right)^{T}
\end{aligned}
$$

where $\omega_{s l}$ is a constant angular velocity, which depends on $W_{b}$ and $T_{t}$. Note if the torque generated by the motor $T_{t}$ is not high enough, then $T_{\mathrm{b}, \mathrm{st}}$ cannot reach the $T_{\mathrm{b}, \mathrm{cf}}$ (breakaway) value, and there will therefore be just one fixed point $\bar{X}_{s t}$. Moreover, in the case of existence, $\bar{X}_{s t}$ is asymptotically stable and $\bar{X}_{s l}$ is locally asymptotically stable [11].

The objective of the controller is to lead the system to $X_{s l}$ (where $\omega_{s l}=\omega_{d}$ ), by changing the control input $T_{t}$. Therefore, a sliding surface similar to the one described in [15] can be defined, and its derivative with respect to time can be calculated as follows:

$$
\begin{aligned}
& s=\left(x_{1}-\omega_{d}\right)+\lambda \int_{t_{0}}^{t}\left(x_{1}-\omega_{d}\right) d \tau+\lambda \int_{t_{0}}^{t}\left(x_{1}-x_{3}\right) d \tau, \\
& \dot{s}=\frac{1}{J_{t}}\left(T_{t}-\left(c_{d}+c_{t}\right) x_{1}+c_{d} x_{3}-k_{d} x_{2}\right)+\lambda\left(x_{1}-\omega_{d}\right)+\lambda\left(x_{1}-x_{3}\right),
\end{aligned}
$$


where $\omega_{d}$ is the desired angular velocity, $t_{0}$ is the starting time of the controller and $\lambda$ is a positive control parameter.

Let us consider what are the states of the system in the sliding surface $(s=0)$. So the $T_{i d}$ can be found from the solution of $\dot{s}=0$ as follows:

$$
T_{i d}=\left(c_{d}+c_{t}\right) x_{1}-c_{d} x_{3}+k_{d} x_{2}-J_{t} \lambda\left(x_{1}-\omega_{d}\right)-J_{t} \lambda\left(x_{1}-x_{3}\right) .
$$

Once the system is on the sliding surface and the model is ideal without any uncertainties and extra un-modelled dynamics, $T_{i d}$ leads the state of the system asymptotically to the desired fixed point $\bar{x}_{s l}\left(\omega_{d}\right)$. This can be proved by using a Lyapunov function such as $V=\frac{1}{2}\left(J_{t}\left(x_{1}-\bar{x}_{s l 1}\right)+k\left(x_{2}-\bar{x}_{s l 2}\right)+J\left(x_{3}-\bar{x}_{s l 3}\right)\right)$. By substituting equation (5.5) into $V$, it can be seen that $\dot{V} \leqslant 0$, and $\dot{V}=0$ for $X=\bar{X}_{s l}\left(\omega_{d}\right)$ [15].

In order to eliminate the uncertainties in the parameters' estimation, the equivalent control, the switching control and eventually a sliding mode controller can be defined in a similar manner as in [15]:

$$
\begin{aligned}
T_{t}= & T_{e q}+T_{s w}, \\
T_{e q}= & \left(\hat{c}_{d}+\hat{c}_{t}\right) x_{1}-\hat{c}_{d} x_{3}+\hat{k}_{d} x_{2}-\hat{J}_{t} \lambda\left(x_{1}-\omega_{d}\right)-\hat{J}_{t} \lambda\left(x_{1}-x_{3}\right), \\
T_{s w}= & -\frac{\epsilon_{c d}\left|x_{1}-x_{3}\right| s}{|s|+\delta_{1} \exp \left(-\delta_{2} \int_{t_{0}}^{t}\left|x_{1}-x_{3}\right| d \tau\right)}-\frac{\epsilon_{c t}\left|x_{1}\right| s}{|s|+\delta_{1} \exp \left(-\delta_{2} \int_{t_{0}}^{t}\left|x_{1}\right| d \tau\right)} \\
& -\frac{\epsilon_{k d}\left|x_{2}\right| s}{|s|+\delta_{1} \exp \left(-\delta_{2} \int_{t_{0}}^{t}\left|x_{2}\right| d \tau\right)}-\frac{\epsilon_{1}-\omega_{d} \mid s}{|s|+\delta_{1} \exp \left(-\delta_{2} \int_{t_{0}}^{t} \lambda\left|x_{1}-\omega_{d}\right| d \tau\right)} \\
& -\frac{\epsilon_{J t} \lambda\left|x_{1}-x_{3}\right| s}{|s|+\delta_{1} \exp \left(-\delta_{2} \int_{t_{0}}^{t} \lambda\left|x_{1}-x_{3}\right| d \tau\right)}-\kappa s,
\end{aligned}
$$

where $\delta_{1}, \delta_{2}$ and $\kappa$ are small positive constants chosen by the designer and ^ denotes the estimated model parameters. $\epsilon_{J t}, \epsilon_{c t}, \epsilon_{c t}$ and $\epsilon_{k d}$ are upper bounds of estimated moments of inertia of the motor, estimated damping coefficients of the motor and the flexible shaft as well as estimated stiffness of the flexible shaft, respectively. Therefore, the following relations are assumed:

$$
\left|\hat{c}_{d}-c_{d}\right| \leqslant \epsilon_{c d}, \quad\left|\hat{c}_{t}-c_{t}\right| \leqslant \epsilon_{c t}, \quad\left|\hat{k}_{d}-k_{d}\right| \leqslant \epsilon_{k d}, \quad\left|\hat{J}_{t}-J_{t}\right| \leqslant \epsilon_{J t} .
$$

The stability of the sliding mode controller $\left(T_{t}=T_{e q}+T_{s w}\right)$ can be proved by defining five extra states $Z=\left[\begin{array}{lllll}z_{1} & z_{2} & z_{3} & z_{4} & z_{5}\end{array}\right]^{T}$ and a new Lyapunov function $\ell$ as follows:

$$
\begin{array}{rlrl}
\ell & =\frac{1}{2} J_{t} s^{2}+\frac{1}{2} \sum_{i=1}^{5} z_{i}^{2}, & z_{1} & =\sqrt{2 \epsilon_{c d} \frac{\delta_{1}}{\delta_{2}} \exp \left(-\delta_{2} \int\left|\dot{x}_{2}\right| d \tau\right)}, \\
z_{2} & =\sqrt{2 \epsilon_{c t} \frac{\delta_{1}}{\delta_{2}} \exp \left(-\delta_{2} \int\left|x_{1}\right| d \tau\right)}, & z_{3} & =\sqrt{2 \epsilon_{k d} \frac{\delta_{1}}{\delta_{2}} \exp \left(-\delta_{2} \int\left|x_{2}\right| d \tau\right)}, \\
z_{4} & =\sqrt{2 \epsilon_{J t} \frac{\delta_{1}}{\delta_{2}} \exp \left(-\delta_{2} \int \lambda\left|x_{1}-\omega_{d}\right| d \tau\right)}, z_{5}=\sqrt{2 \epsilon_{J t} \frac{\delta_{1}}{\delta_{2}} \exp \left(-\delta_{2} \int \lambda\left|x_{1}-x_{3}\right| d \tau\right)} .
\end{array}
$$


As $t \rightarrow \infty, z_{i}$ is exponentially convergent to zero, leading to $\ell \rightarrow 0$ when $s=0$. Therefore, $\ell$ defined in equation (5.10) is a legitimate Lyapunov function with state variable $\left[s, z^{T}\right]^{T}$. The time derivative of $\ell$ is given by

$$
\begin{aligned}
\dot{\ell}= & J_{t} s \dot{s}-\epsilon_{c d} \delta_{1}\left|\dot{x}_{2}\right| \exp \left(-\delta_{2} \int\left|\dot{x}_{2}\right| d \tau\right)-\epsilon_{c t} \delta_{1}\left|x_{1}\right| \exp \left(-\delta_{2} \int\left|x_{1}\right| d \tau\right) \\
& -\epsilon_{k d} \delta_{1}\left|x_{2}\right| \exp \left(-\delta_{2} \int\left|x_{2}\right| d \tau\right)-\epsilon_{J t} \delta_{1} \lambda\left|x_{1}-\omega_{d}\right| \exp \left(-\delta_{2} \int \lambda\left|x_{1}-\omega_{d}\right| d \tau\right), \\
& -\epsilon_{J t} \delta_{1} \lambda\left|x_{1}-x_{3}\right| \exp \left(-\delta_{2} \int \lambda\left|x_{1}-x_{3}\right| d \tau\right)
\end{aligned}
$$

Substituting equation (5.8) into equation (5.11), it can be seen $\ell \leqslant-\kappa s^{2} \leqslant 0$ and $\dot{\ell}=0$ for $s=0$ [15]. Therefore, using the controller, any trajectory of the system will reach and stay thereafter on the manifold $s=0$ asymptotically. Therefore, as explained before, the state of the system will asymptotically converge to the desired fixed point $X=\bar{X}_{s l}\left(\omega_{d}\right)$.

\subsection{Numerical results}

In order to evaluate the effectiveness of the proposed controller, numerical analysis is carried out. First, the stick-slip vibration is simulated, and then the controller is activated to suppress the vibration. Therefore, the identified parameters of the experiment are used, including TOB parameters for $W_{b}=1.79 \mathrm{kN}$. The remaining parameters for both cases are presented in Table 1 . Note that the estimated parameters are chosen close to the identified parameters of the experimental rig while satisfying equation (5.9).

Time histories of angular velocities of the motor (black) and drill-bit (green), control signals (blue) and phase portraits of two simulations using sliding mode controller are shown in Figure 4. It can be seen here, that the controllers are switched on at $t=30 \mathrm{~s}$ while the drill-bit exhibits stick-slip vibration. Figures 4(c) and (d) show the phase portraits of both examples, where the stick-slip trajectories are shown in green. The blue parts of the curves in both phase portraits, show how the controller leads the system to the desired fixed points. In the first example, Figures 4(a) and (c), the desired velocity $\omega_{d}$ is $3.1 \mathrm{rad} / \mathrm{s}$ and the control parameter $\lambda$ is 0.8 , whereas for the second example, Figures $4(\mathrm{~b})$ and (d), $\omega_{d}$ is $5 \mathrm{rad} / \mathrm{s}$ and $\lambda$ is 1 . The rest of the control parameters for both examples are as follows: $\delta_{1}=0.01, \delta_{2}=1.00 E-5$ and $\kappa=1$.

\section{Experimental verification of the control method}

To validate the numerical results, the sliding mode controller is implemented in LabVIEW. As mentioned earlier, the frequency converter is used to control the motor's torque, which means that the input signal produced in LabVIEW goes to the frequency converter and its output goes to the motor. In previous section, we modelled the experimental rig assuming the motor follows the input signal accurately and without delay. In order to evaluate the performance of the frequency converter and investigate the possible delay in the motor, we focus first at the torque generated by the motor which should ideally follow the input 
(a)
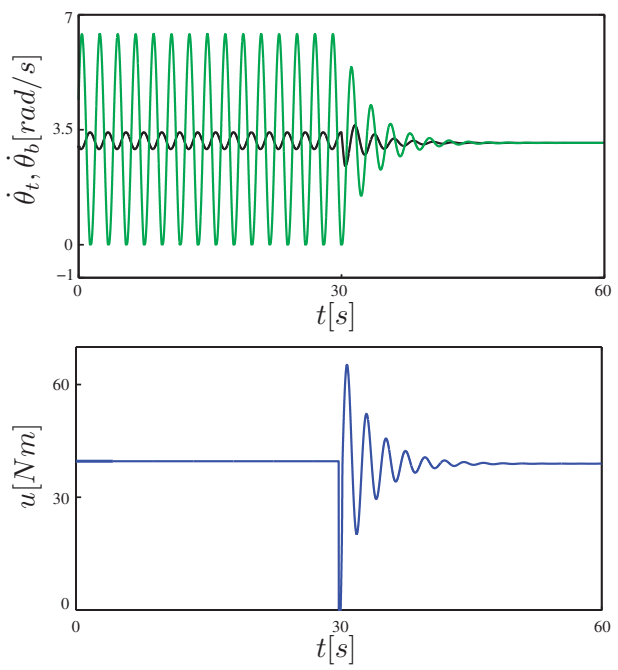

(c)

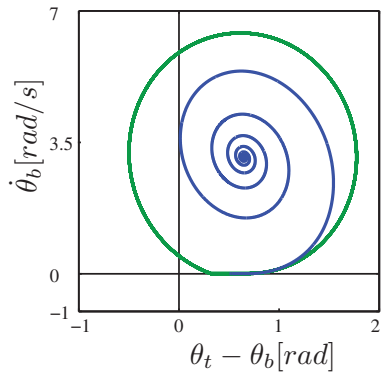

(b)
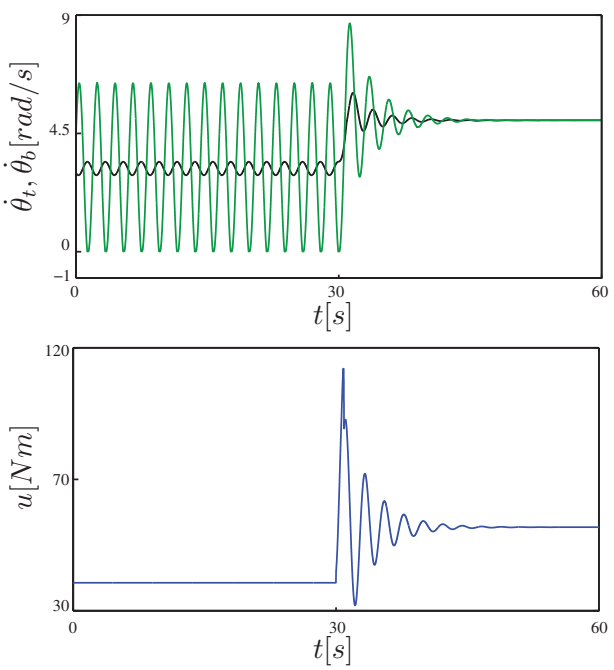

(d)

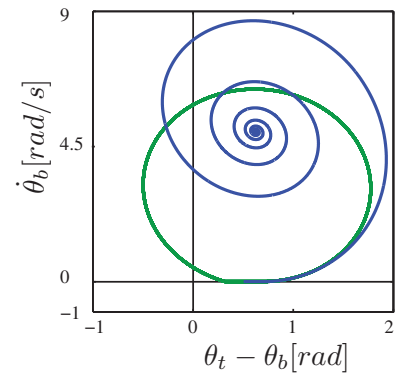

FIGURE 4. Time histories of top angular velocity (blacks), drill-bit angular velocity (green) and control signal (blue) of the simulations using sliding mode controller with (a) $\omega_{d}=3.1 \mathrm{rad} / \mathrm{s}$ and $\lambda=0.8$ and (b) $\omega_{d}=5 \mathrm{rad} / \mathrm{s}$ and $\lambda=1$. The controllers are switched on at $t=30 \mathrm{~s}$. The stick-slip trajectories and the trajectories to the desired fixed points are shown in green and blue, respectively, in phase portraits (c) and (d).

signal. Time histories of control signals are depicted in Figure 5, where the estimated torque generated by the motor $\left(\hat{T}_{t}\right.$, red) shows a delay with respect to the input signal ( $T_{c}$, blue). The control parameter $\left(T_{c}\right)$ of this converter and the estimated torque $\left(\hat{T}_{t}\right)$ are expressed as a percentage of the full capacity of the motor, as required in the experimental system. The delay was determined from several tests and averaged to a value of $0.40 \mathrm{~s}$. In addition, it can be seen in Figure 5 that the motor produces a minimum torque of $22.62 \mathrm{~N} \mathrm{~m}$ when the delayed input signal, $T_{c}(t-0.4)$, is zero. The details of this estimation can be found in [17]. Considering the time delay and the minimum motor's torque (dead zone) observed in the actuator, a new structure is shown for the sliding mode controller in Figure 6.

After estimating motor's delay, several experiments have been carried out to validate the numerical results obtained in the previous section. In Figure 7, time histories of angular 


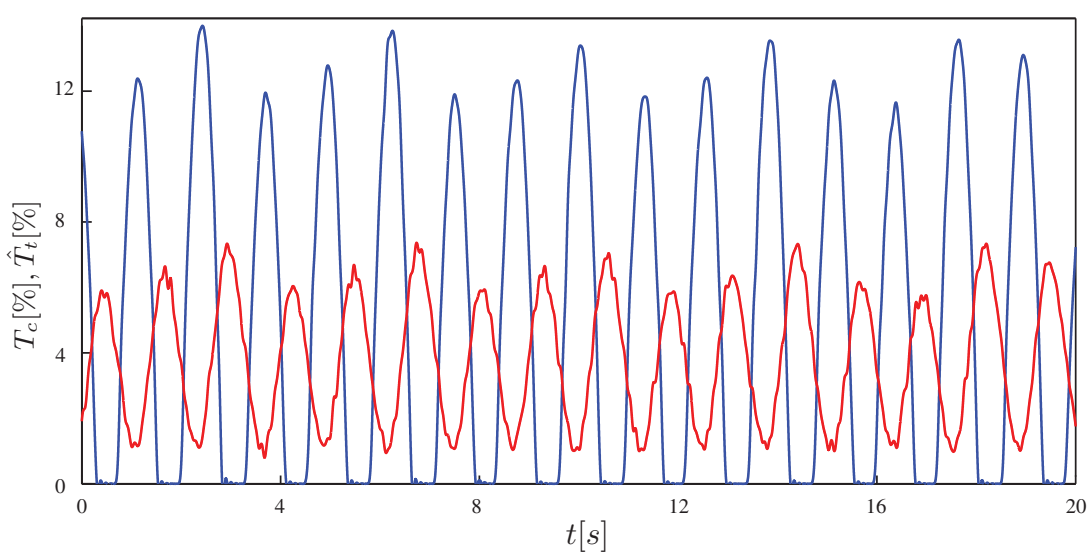

FIGURE 5. Time histories of the actuator input value $T_{c}$ and the estimated torque generated by motor $\hat{T}_{t}$ in blue and red, respectively. Note that the control parameters are expressed as a percentage of the full capacity of the motor, as required in the experimental system.

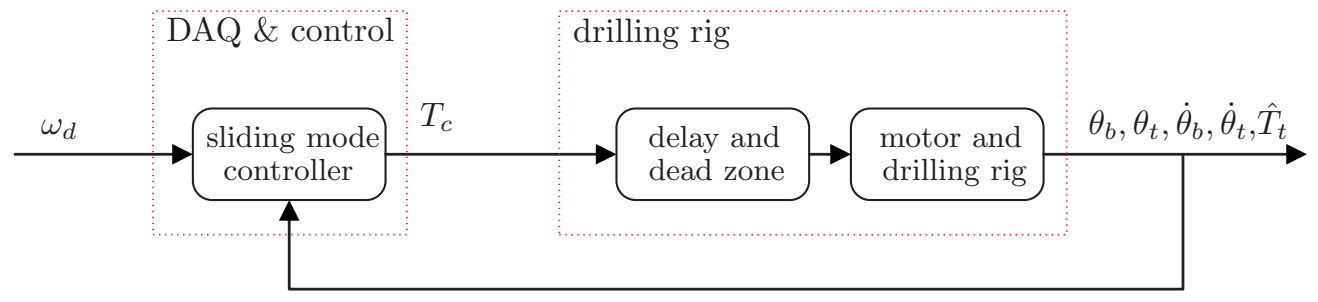

FIGURE 6. The structure of the suggested sliding mode controller for the experimental rig with delay and dead zone. A $0.4 \mathrm{~s}$ delay and a minimum $22.62 \mathrm{Nm}$ torque are observed in the motor.

velocities of the motor (black) and the drill-bit (red), control signals (blue) and phase portraits of two experiments using sliding mode controller are shown for two different cases. As can be seen, the controllers are switched on at $t=30 \mathrm{~s}$, while the drill-bit is in the stick phase. The controller succeeds in eliminating the stick-slip vibration and reducing significantly the amplitude of the drill-bit oscillations. These can be seen in phase portraits where the system trajectories before and after switching on the controller, are shown in red and blue, respectively. In the first example, Figures 7(a) and (c), the desired angular velocity $\omega_{d}$ is $3.1 \mathrm{rad} / \mathrm{s}$ and the control parameter $\lambda$ is 0.8 , whereas for the second example, Figures 7(b) and (d), $\omega_{d}$ is $5 \mathrm{rad} / \mathrm{s}$ and $\lambda$ is 1 . The rest of the control parameters and estimated physical parameters are the same, as for the simulations presented in Figure 4. However, unlike in the simulation, the controller could not lead the drill-bit to the constant velocity. Note that the delay in the motor was not considered in the simulation.

To improve the accuracy of the model, the motor delay and the dead zone are added to the simulation. Figure 8 shows time histories of angular velocities of the motor (black) and the drill-bit (green), control signals (blue) and phase portraits of two simulations using sliding mode controller. The parameters including physical parameters, estimated 
(a)
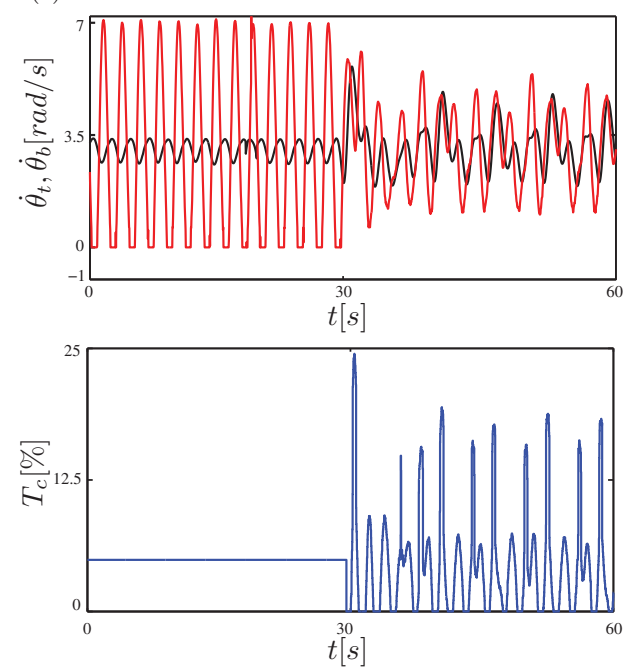

(c)

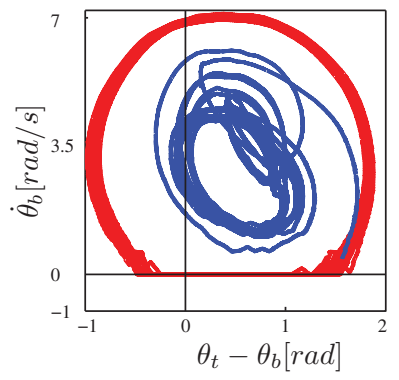

(b)
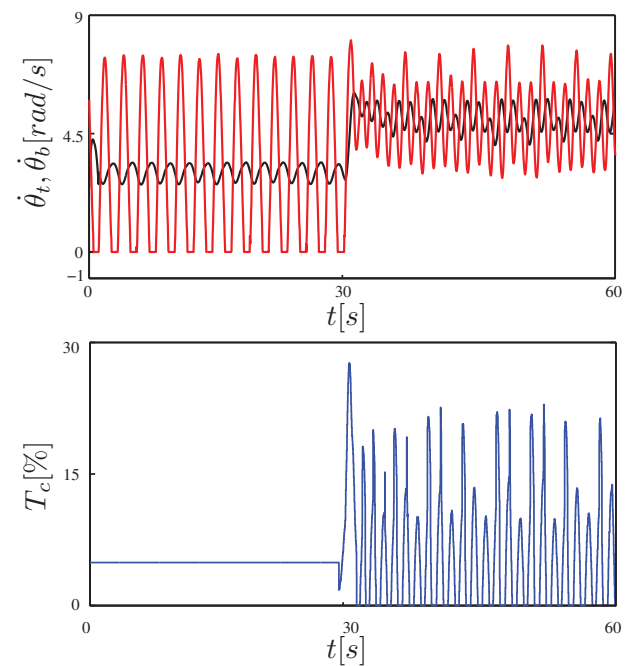

(d)

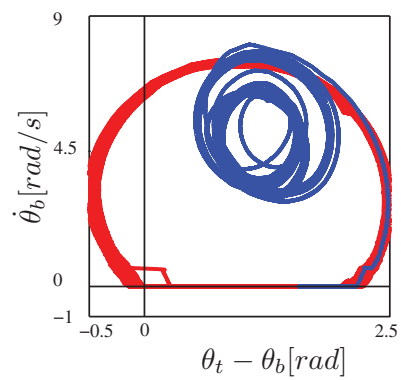

Figure 7. Time histories of top angular velocity, drill-bit angular velocity and control signal of the drilling experiment using sliding mode controller with (a) $\omega_{d}=3.1 \mathrm{rad} / \mathrm{s}$ and $\lambda=0.8$ and (b) $\omega_{d}=5 \mathrm{rad} / \mathrm{s}$ and $\lambda=1$ shown in black, red and blue, respectively. The stick-slip trajectories and the limit cycles are shown in red and blue, respectively, in phase portraits (c) and (d).

parameters and control parameters are the same as in the previous cases. These simulation results show that the system converges to a limit cycle as in the experimental results presented in Figure 7.

It has been observed that in the presence of the delay in the actuator in some cases, when the controller is switched off, the system goes back to the stick-slip vibration. An example of this phenomena and its corresponding simulation results are presented in Figure 9. The controller is on in two time intervals $[30.6,60.6] \mathrm{s}$ and $[110.45,150.4] \mathrm{s}$, as depicted in blue in Figure 9. The red lines in the lower panel of these figures represent the average control effort, while using the proposed control method in the experiment and simulation. All parameters used for these studies are the same as the ones in Figures 7 and 8.

In order to evaluate the sensitivity to the parameter estimation in the experimental results, the vibration reduction factor (VRF) is defined as $\mathrm{VRF}=A_{c} / A_{u n} \%$, where $A_{c}$ 
(a)
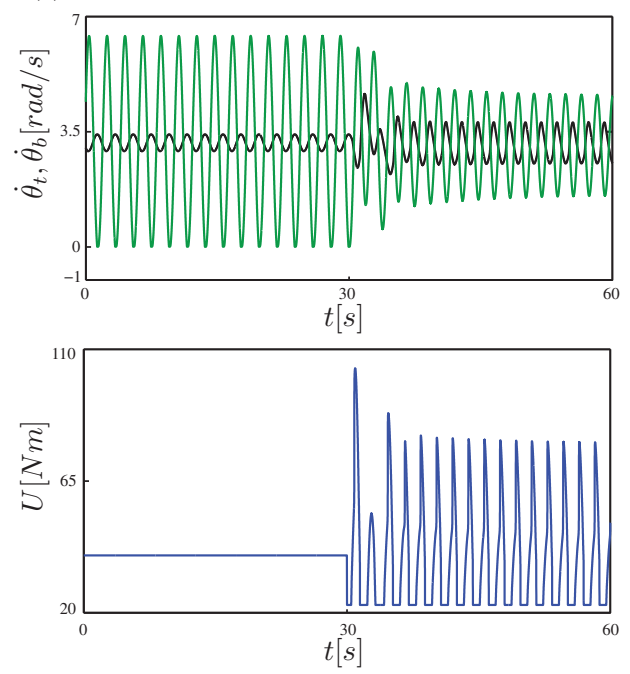

(c)

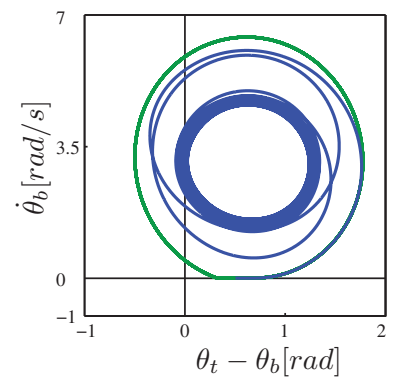

(b)
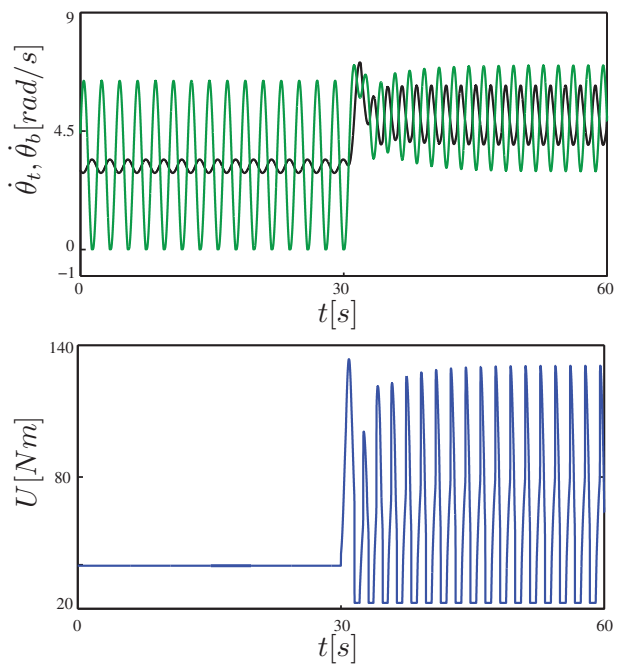

(d)

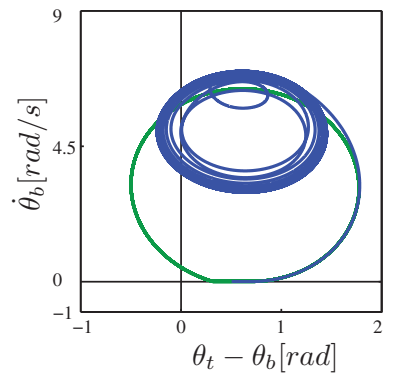

Figure 8. Time histories of top angular velocity (black), drill-bit angular velocity (green), and control signal (blue) of a simulation considering a $0.4 \mathrm{~s}$ delay and minimum of $22.62 \mathrm{~N} \mathrm{~m}$ torque in motor using sliding mode controller with (a) $\omega_{d}=3.1 \mathrm{rad} / \mathrm{s}$ and $\lambda=0.8$ and (b) $\omega_{d}=5 \mathrm{rad} / \mathrm{s}$ and $\lambda=1$. The controllers are switched on at $t=30 \mathrm{~s}$. The stick-slip trajectories and the limit cycles are shown in green and blue, respectively, in phase portraits (c) and (d). This result is very close to the experiment presented in Figure 7.

is amplitude of the 'vibration' when the sliding mode controller is applied and $A_{u n}$ is amplitude of 'stick-slip vibration' when the controller is off. VFR is calculated based on the results obtained in several experiments with a variety of estimated parameters. Table 2 shows the parameters used in the experiments as well as corresponding VFRs. Figure 10 presents phase portraits of theses experiments, where the uncontrolled stickslip trajectories and the controlled limit cycles are shown in red and blue, respectively. These results show that the controller achieves (a) $47.86 \%$, (b) $59.26 \%$, (c) $51.52 \%$, (d) $57.58 \%$, (e) $66.72 \%$ and (f) $64.72 \%$ reduction in vibration amplitude. Therefore, in these range of parameters, the sliding mode controller was successful in reducing the drill-bit vibration. 
(a)
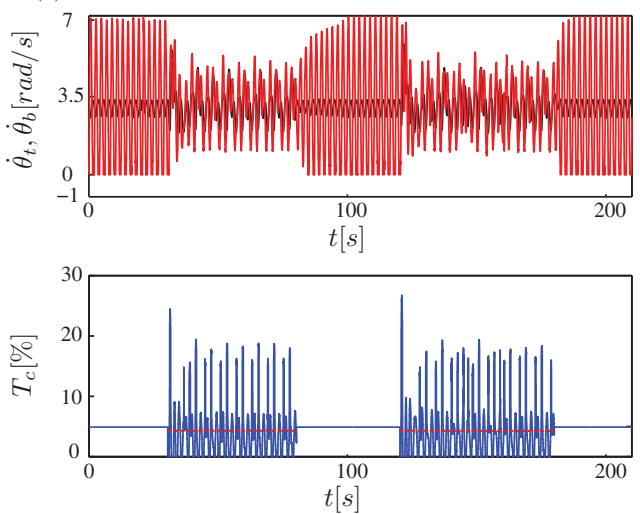

(b)
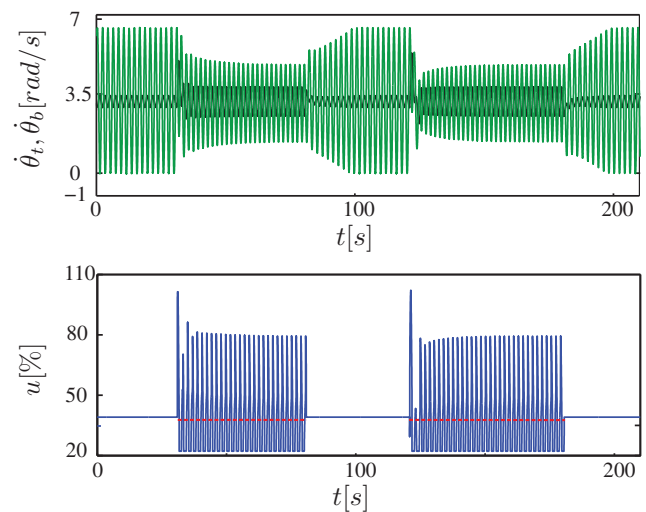

FIGURE 9. Time histories of top angular velocity (black), drill-bit angular velocity (red) and control signal (blue) of the drilling experiment (a) and its corresponding simulation results (b) activating the controller in two time intervals $[30.6,60.6] \mathrm{s}$ and $[110.45,150.4] \mathrm{s}$. The red line in the lower panel is the average control effort while using the proposed control method. The controller achieves elimination of the stick-slip vibration in the drill-bit (red). All parameters used for this experiment are the same as the ones in Figures 7 and 8.

(a)

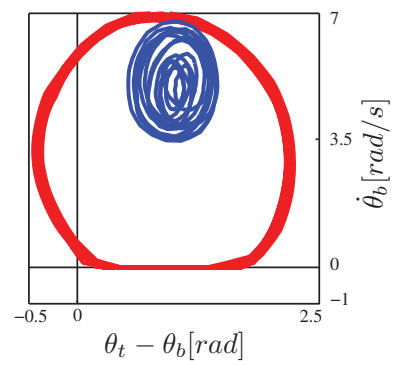

(d)

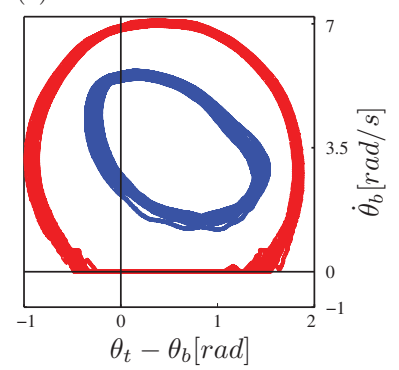

(b)

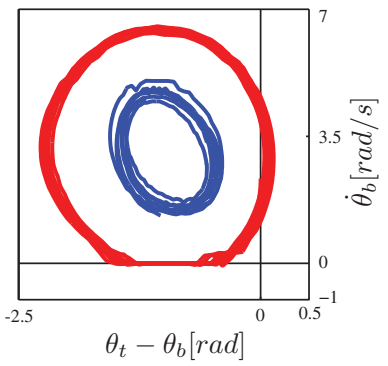

(e)

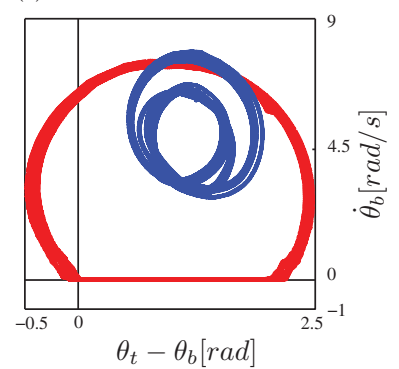

(c)

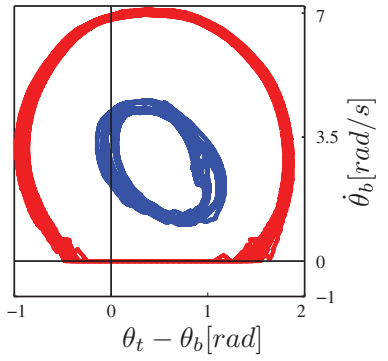

(f)

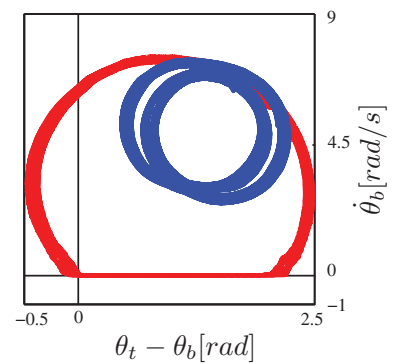

FIGURE 10. Phase portraits of the drilling experiments using sliding mode controller. The uncontrolled stick-slip trajectories and the controlled limit cycles are shown in red and blue, respectively. All estimated parameters, boundaries and controller parameters used in these experiments are presented in Table 2. The controller achieves (a) $47.86 \%$, (b) $59.26 \%$, (c) $51.52 \%$, (d) $57.58 \%$, (e) $66.72 \%$ and (f) $64.72 \%$ reduction in vibration. 
Table 2. The estimated parameters used in experiments (Figure 10) and the corresponding results

\begin{tabular}{lcccccc} 
Parameter & $(\mathrm{a})$ & $(\mathrm{b})$ & $(\mathrm{c})$ & $(\mathrm{d})$ & $(\mathrm{e})$ & $(\mathrm{f})$ \\
\hline$\omega_{d}[\mathrm{rad} / \mathrm{s}]$ & 5 & 3.1 & 3.1 & 3.1 & 5 & 5 \\
$\lambda$ & 0.4 & 0.4 & 0.8 & 0.4 & 1 & 1 \\
$\delta_{1}$ & 0.01 & 0.01 & 0.01 & 0.01 & 0.01 & 0.01 \\
$\delta_{2}$ & 0.00001 & 0.00001 & 0.00001 & 0.00001 & 0.00001 & 0.00001 \\
$\kappa$ & 1 & 1 & 1 & 1 & 1 & 1 \\
$\hat{c}_{t}[\mathrm{~N} \mathrm{~m} \mathrm{~s} / \mathrm{rad}]$ & 0.0051 & 0.0051 & 0.0051 & 0.0051 & 0.0051 & 0.0051 \\
$\epsilon_{c d}$ & 0.00255 & 0.00255 & 0.00255 & 0.00255 & 0.00255 & 0.00255 \\
$\hat{k}_{d}[\mathrm{~N} \mathrm{~m} / \mathrm{rad}]$ & 10 & 10 & 10 & 10 & 10 & 10 \\
$\epsilon_{k d}$ & 5 & 5 & 5 & 5 & 5 & 5 \\
$\hat{c}_{t}[\mathrm{~N} \mathrm{~m} \mathrm{~s} / \mathrm{rad}]$ & 2.91 & 2.91 & 10.45 & 10.45 & 10.45 & 10.45 \\
$\epsilon_{c t}$ & 1.45 & 1.45 & 3 & 2 & 3 & 2 \\
$\hat{J}_{t}\left[\mathrm{~kg} / \mathrm{m}^{2}\right]$ & 6.356 & 6.356 & 13.92 & 13.92 & 13.92 & 13.92 \\
$\epsilon_{J t}$ & 3.2 & 3.2 & 2 & 2 & 2 & 2 \\
$\mathrm{VRF}[\%]$ & 47.86 & 59.26 & 51.52 & 57.58 & 66.72 & 64.72 \\
\hline \hline
\end{tabular}

\section{Conclusions}

In this paper, we investigated experimentally and numerically suppression of drill-string torsional vibration while drilling by using a sliding mode controller. The experiments were conducted on the novel experimental drill-string dynamics rig developed at the University of Aberdeen [1], that uses commercial PDC drill-bits and rock-samples. First, we have presented a two degrees-of-freedom model for the drilling rig, where the top motor and the gearing system as well as the BHA and the drill-bit have been represented by two disks. The first disk is subjected to a driving and a viscous drag torque, while the second one is subjected to the reaction torque coming from interaction of the drill-bit and the formation, which consists of the cutting torque and the friction torque. We identified the parameters of the model and calibrated it by conducting several systematic experiments, achieving a good match between the experiment and the simulation.

The next step of this study was to adapt a sliding mode control method and apply it to the proposed model, in order to eliminate stick-slip vibration both in the drilling rig and the simulation. The Lyapunov stability of the controller is proven in presence of model parameter uncertainties, by defining a robust Lyapunov function. The controller is successful in suppressing the vibration and bringing the system to the desired fixed point. The controller implemented in this experiment is successful in eliminating stick-slip during the experiments as well. However, as a results of a delay and a dead zone observed in the actuator, a limit cycle is observed around the desired fixed point. Adding these to the two degrees-of-freedom model achieves an excellent match between the experiment and the simulation. In order to examine the sensitivity of the controller to the parameters, several experiments were carried out with a variety of estimated parameters applied to the controller. A significant reduction in vibration amplitude is observed when the controller is applied. 
Taking into consideration the positive experimental results reported in this paper, we can conclude that a robust mathematical model capable of accurately predicting the responses of the analyzed experimental setup and a sliding mode controller, that succeeds in eliminating the stick-slip vibration in presence of the delay in the actuator, have been developed. One of the subsequent steps could be improving the controller to deal with common delay problems in the motor and the gearing systems or in the data acquisition procedure. Alternatively, a fast-response motor system can be installed in the experimental rig in order to avoid a limit cycle in the response of the system. It is worth mentioning that in the presented control method the downhole measurements have been used which might not be available in most drilling rigs in the field. One of the possible solution to overcome this challenge would be use of the observer to estimate the bit-velocity, which is used in this control method.

\section{Acknowledgements}

The authors wish to thank BG Group plc for the financial support to this research. They would also like to express their gratitude to Dr. K. Nandakumar of Lloyd Register and Dr. Y. Liu of University of Exeter for their valuable contributions in this project and to Mr. N. Bardas, R. Stephen and G. McFarlane at Aberdeen University for their technical support while running the experimental rig.

\section{References}

[1] Wiercigroch, M. (2010) Modelling and Analysis of BHA and Drill-string Vibrations. R\&D project sponsored by the BG Group.

[2] Spanos, P., Chevallier, A., Politis, N. \& Payne, M. (2003) Oil and gas well drilling: A vibrations perspective. Shock Vib. Dig. 35(2), 81-99.

[3] BRetT, J. (1992) The genesis of torsional drillstring vibrations. SPE Drill Eng. 7(3), 168-174.

[4] Richard, T., Germay, C. \& Detournay, E. (2007) A simplified model to explain the root cause of stick-slip vibrations in drilling systems with drag bits. J. Sound. Vib. 305, 432-456.

[5] Germay, C., Denoel, V. \& Detournay, E. (2009) Multiple mode analysis of the self-excited vibrations of rotary drilling systems. J. Sound Vib. 325, 362-381.

[6] Besselink, B., van de Wouw, N. \& NiJmeijer, H. (2011) A semi-analytical of stick-slip oscillations in drilling systems. ASME J. Comput. Nonlinear Dyn. 6, 021006-1-021006-9.

[7] Saldivar, B., Mondié, S., Niculescu, S.-I., Mounier, H. \& Boussaada, I. (2016) A control oriented guided tour in oilwell drilling vibration modeling. Annu. Rev. Control 42, 100-113.

[8] Detournay, E. \& Defourny, P. (1992) A phenomenological model for the drilling action of drag bits. Int. J. Rock Mech. Mining Sci. 29(1), 13-23.

[9] Detournay, E., Richard, T. \& Shepherd, M. (2008) Drilling response of drag bits: Theory and experiment. Int. J. Rock Mech. Min. Sci. 45, 1347-1360.

[10] Ghasemloonia, A., Geoff Rideout, D. \& Butt, S. D. (2015) A review of drillstring vibration modeling and suppression methods. J. Pet. Sci. Eng. 131, 150-164.

[11] Navarro-López, E. \& LicÉaga-Castro, E. (2009) Non-desired transitions and sliding-mode control of a multi-DOF mechanical system with stick-slip oscillations. Chaos, Solitons Fractals 41(4), 2035-2044.

[12] Navarro-LóPez, E. \& Cortés, D. (2007) Avoiding harmful oscillations in a drillstring through dynamical analysis. J. Sound Vib. 307(1-2), 152-171. 
[13] Navarro-López, E. M. \& SuÁrez, R. (2004) Practical approach to modelling and controlling stick-slip oscillations in oilwell drillstrings. In: IEEE International Conference on Control Applications, pp. 1454-1460.

[14] Navarro-LóPEz, E. (2009) An alternative characterization of bit-sticking phenomena in a multi-degree-of-freedom controlled drillstring. Nonlinear Anal.: Real World Appl. 10(5), 31623174.

[15] LiU, Y. (2015) Suppressing stick-slip oscillations in underactuated multibody drill-strings with parametric uncertainties using sliding-mode control. IET Control Theory Appl. 9(1), 91-102.

[16] Vromen, T., Dai, C.-H., Van De Wouw, N., Oomen, T., Astrid, P. \& Nijmeijer, H. (2015) Robust output-feedback control to eliminate stick-slip oscillations in drill-string systems. IFAC-papersonline 48(6), 266-271.

[17] Vaziri Hamaneh, S. V. (2015) Dynamics and Control of Nonlinear Engineering Systems, PhD Thesis, University of Aberdeen, Aberdeen, UK.

[18] Navarro-López, E. \& Carter, R. (2016) Deadness and how to disprove liveness in hybrid dynamical systems. Theor. Comput. Sci. 642, 1-23.

[19] Zhu, X., TANG, L. \& YANG, Q. (2014) A literature review of approaches for stick-slip vibration suppression in oilwell drillstring. Adv. Mech. Eng. 6, 967952.

[20] Wu, X., Paez, L. C., Partin, U. T. \& Agnihotri, M. (2010) Decoupling stick/slip and whirl to achieve breakthrough in drilling performance. In: SPE/IADC Drilling Conference, SPE128767-MS.

[21] Patil, P. A. \& Teodoriu, C. (2013) A comparative review of modelling and controlling torsional vibrations and experimentation using laboratory setups. J. Pet. Sci. Eng. 112, 227-238.

[22] Jansen, J. \& VAn den Steen, L. (1995) Active damping of self-excited torsional vibrations in oil well drillstrings. J. Sound Vib. 179(4), 647-668.

[23] Serrarens, A., van de Molengraft, M., KoK, J. \& van den Steen, L. (1998) $\mathrm{H}_{\infty}$ control for suppressing stick-slip in oil well drillstrings. IEEE Control Syst. Mag. 18(2), 19-30.

[24] Al Sairafi, F. A., Al Ajmi, K. E., Yigit, A. S. \& Christoforou, A. P. (2016) Modeling and control of stick slip and bit bounce in oil well drill strings. In: SPE/IADC Middle East Drilling Technology Conference and Exhibition, SPE-178160-MS.

[25] Pehlivanturk, C., Chen, D. \& van Oort, E. (2017) Torsional drillstring vibration modelling and mitigation with feedback control. In: SPE/IADC Drilling Conference and Exhibition, SPE-184697-MS.

[26] Tucker, R. \& Wang, C. (1999) On the effective control of torsional vibrations in drilling systems. J. Sound Vib. 224, 101-122.

[27] Navarro-López, E. \& Cortés, D. (2007) Sliding-mode control of a multi-DOF oilwell drillstring with stick-slip oscillations. In: Proceedings of the American Control Conference, p. 3837.

[28] Hernandez-Suarez, R., Puebla, H., Aguilar-Lopez, R. \& Hernandez-Martinez, E. (2009) An integral high-order sliding mode control approach for stick-slip suppression in oil drillstrings. Pet. Sci. Technol. 27(8), 788-800.

[29] Bayliss, M. T., Panchal, N. \& Whidborne, J. (2012) Rotary steerable directional drilling stick/slip mitigation control. IFAC Proc. Vol. 45(8), 66-71.

[30] Gabler, T. \& BAKENOv, A. (2003) Enhanced drilling performance through controlled drillstring vibrations. In: AADE Technical Conference, AADE-03-NTCE-21, pp. 1-8.

[31] Carlos-de-Wit, C., Corchero, M. A., Rubio, F. R. \& Navarro-López, E. M. (2005) DOSKIL: A new mechanism for suppressing stick-slip in oil well drillstrings. In: 44th IEEE Conference on Decision and Control, pp. 8260-8265.

[32] Lu, H., Dumon, J. \& Canudas-De-Wit, C. (2009) Experimental study of the D-OSKIL mechanism for controlling the stick-slip oscillations in a drilling laboratory testbed. In: IEEE Multi-Conference on Systems and Control.

[33] Puebla, H. \& Alvarez-Ramirez, J. (2008) Suppression of stick-slip in drillstrings: A control approach based on modeling error compensation. J. Sound Vib. 310, 881-901. 
[34] Hong, L., Girsang, I. P. \& Dhupia, J. S. (2016) Identification and control of stick-slip vibrations using Kalman estimator in oil-well drill strings. J. Pet. Sci. Eng. 140, 119-127.

[35] Mihajlović, N., Van Veggel, A., van de Wouw, N. \& NiJmeijer, H. (2004) Analysis of friction-induced limit cycling in an experimental drill-string system. ASME J. Dyn. Syst., Meas, Control 126(4), 709-720.

[36] Liao, C., Balachandran, B. \& Karkoub, M. (2009) Drillstring dynamics: Reduced-order models. In: ASME International Mechanical Engineering Congress and Exposition (IMECE 2009-10339).

[37] Melakhessou, H., Berlioz, A. \& Ferraris, G. (2003) A nonlinear well-drillstring interaction model. Trans. ASME J. Vib. Acoust. 125(1), 46-52.

[38] Khulief, Y. A. \& Al-Sulaiman, F. A. (2009) Laboratory investigation of drill-string vibration. Proc. IMech E, Part C: J. Mech. Eng. Sci. 223, 2249-2262.

[39] Raymond, D. W., Elsayed, M. A., Polsky, Y. \& Kuszmaul, S. S. (2008) Laboratory simulation of drill bit dynamics using a model-based servohydraulic controller. J. Energy Resour. Technol. 130(4), 043103.

[40] Hoffmann, O. (2006) Drilling Induced Vibration Apparatus, PhD Thesis, University of Minnesota, Minnesota, US.

[41] Franca, L. F. (2010) Drilling action of roller-cone bits: Modeling and experimental validation. J. Energy Resources Technol. 132(4), 043101.

[42] Kapitaniak, M., Vaziri Hamaneh, S., Páez Chávez, J., Nandakumar, K. \& Wiercigroch, M. (2015) Unveiling complexity of drill-string vibrations: Experiments and modelling. Int. J. Mech. Sci. 101-102, 324-337.

[43] Slotine, J. \& Weiping, L. (1991) Applied Nonlinear Control, Prentice-Hall, Englewood Cliffs, NJ, US. 